\title{
Neuroactive steroids and their role in epilepsy
}

\author{
Chetan Y. Patil", Shamsundar A. Jadhav, Sudhakar M. Doifode, Mirza Shiraz Baig
}

Department of Pharmacology, Government Medical College and Hospital, Aurangabad431001, Maharashtra, India

Received: 18 October 2012 Accepted: 31 October 2012

\section{*Correspondence to:}

Dr. Chetan Y. Patil,

Email:

drchetanpatil.gmc@gmail.com

\begin{abstract}
Neuroactive steroids are the certain steroids that alter neuronal excitability via the cell surface through interaction with certain neurotransmitter receptors. Neuroactive steroids regulate physiological functions of the central nervous system and have possible therapeutic potential in neurological diseases. They have been shown to affect neuronal excitability via their interaction with the ligand-gated ion channel family, such as the $\mathrm{GABA}_{\mathrm{A}}$ receptor by acting genomically as well as nongenomically. Positive modulators of $\mathrm{GABA}_{\mathrm{A}}$ receptor have anticonvulsant action as they enhance GABAergic transmission thereby increasing the seizure threshold. By virtue of these properties, neurosteroids appear to be relevant to pathophysiology and pharmacological treatment of many neurological diseases including catamenial epilepsy, stress induced epilepsy, temporal lobe epilepsy, alcohol withdrawal seizures, infantile spasm and status epilepticus. So far, only synthetic neurosteroid, ganaxolone has been tried in treatment of epilepsy and has shown good efficacy and tolerability. But, human data of trials are limited and hence, large double-blinded, placebo-controlled, randomized clinical trials are required before their use. The paper reviews the biosynthesis and $\mathrm{GABA}_{\mathrm{A}}$ receptor modulation of neurosteroids and their potential role in epilepsy.
\end{abstract}

Keywords: Neuroactive steroids, Neurosteroids, Allopregnanolone, Tetrahydrodeoxycorticosterone (THDOC), $\mathrm{GABA}_{\mathrm{A}}$ receptor, Catamenial epilepsy, Seizure, Epilepsy

\section{INTRODUCTION}

Steroid hormones act as transcription factors and regulate gene expression which is exerted by binding to their respective intracellular receptors. ${ }^{1}$ However, certain steroids may alter neuronal excitability via the cell surface through interaction with certain neurotransmitter receptors. The term 'neuroactive steroid' has been coined for steroids with these particular properties. Molecular basis for the action of neurosteroids is explained by their genomic effects (limited by the rate of protein biosynthesis and requiring a time period from minutes to hours) and nongenomic effects (the modulatory effects requiring only milliseconds to seconds). This provides a broad spectrum action of neuroactive steroids on neuronal function and plasticity. ${ }^{1}$ Neuroactive steroids also act on various neurotransmitter receptors and voltage-dependent ion channels, especially $\gamma$ aminobutyric acid (GABA), $N$-methyl-D-aspartate (NMDA), $\quad \alpha$-amino-3-hydroxy-5-methyl-4isoxazolepropionic acid (AMPA), kainate, glycine, serotonin, sigma-1, nicotinic and muscarinic acetylcholine receptors, as well as T-type $\mathrm{Ca}^{+2}$ channel, high voltage-activated $\mathrm{Ca}^{+2}$ channel, $\mathrm{Na}^{+}$channel, $\mathrm{Ca}^{+2}-$ activated $\mathrm{K}$ channel, and anion channels. ${ }^{2}$

In general, neuroactive steroids are the steroids which regulate the neuronal activities and physiological functions of the CNS., ${ }^{2,3}$ They are classified as endogenous steroids and exogenous (synthetic) steroids based on the source or production site. Endogenous steroids are subdivided into hormonal steroids (produced by the endocrine glands) and neurosteroids (produced by the nervous tissue) [Figure 1]. ${ }^{2}$

Neuroactive steroids have shown numerous important modulatory effects on brain functions and brain diseases. These effects are exerted by modulating almost all kinds of classical synaptic transmission including glutamatergic, GABAergic, cholinergic, noradrenergic, dopaminergic and serotonergic synaptic transmission, either by altering the responsiveness of postsynaptic receptors or by the presynaptic release of neurotransmitters. $^{2}$ As they modulate GABAergic transmission, endogenous neurosteroids though to play a role in the physiological regulation of seizure 
susceptibility in individuals with epilepsy. Many studies have proven that they play important roles in the pathology and treatment of neurological disorders including, epilepsy such as catamenial epilepsy, childhood epilepsy, stress induced seizures, temporal lobe epilepsy, alcohol withdrawal seizure, infantile spasm and status epilepticus. However, there is no evidence that alterations in neurosteroid levels can cause epileptogenesis in the absence of pre-existing epilepsy. ${ }^{4}$

\section{BIOSYNTHESIS OF NEUROSTEROIDS}

Endogenous neuroactive steroids can be synthesized de novo in the brain as well as in adrenal glands, ovaries and testes. Among these compounds, the $3 \alpha, 5 \alpha-$ and $3 \alpha, 5 \beta$ reduced metabolites of progesterone $(3 \alpha, 5 \alpha-$ and $3 \alpha, 5 \beta$ - tetrahydroprogesterone), deoxycorticosterone ( $3 \alpha, 5 \alpha-$ and $3 \alpha, 5 \beta$ tetrahydrodeoxycorticosterone), dehydroepiandrosterone (DHEA) $(3 \alpha, 5 \alpha-$ and $3 \alpha, 5 \beta-$ androsterone) and testosterone $(3 \alpha, 5 \alpha-$ and $3 \alpha, 5 \beta-$ androstanol) enhance GABAergic neurotransmission and produce inhibitory neurobehavioral effects such as anticonvulsant, anxiolytic and sedative actions. The excitatory neuroactive steroids include the sulfated derivatives of pregnenolone and DHEA as well as the $3 \alpha$, $5 \alpha$ - and $3 \alpha$, $5 \beta$-reduced metabolites of cortisol. ${ }^{1,5,6}$ The biosynthetic pathway for these steroids is shown in Figure $2 .^{5}$

\section{NOMENCLATURE}

The nomenclature of the steroids is provided in Table $1 .^{5}$

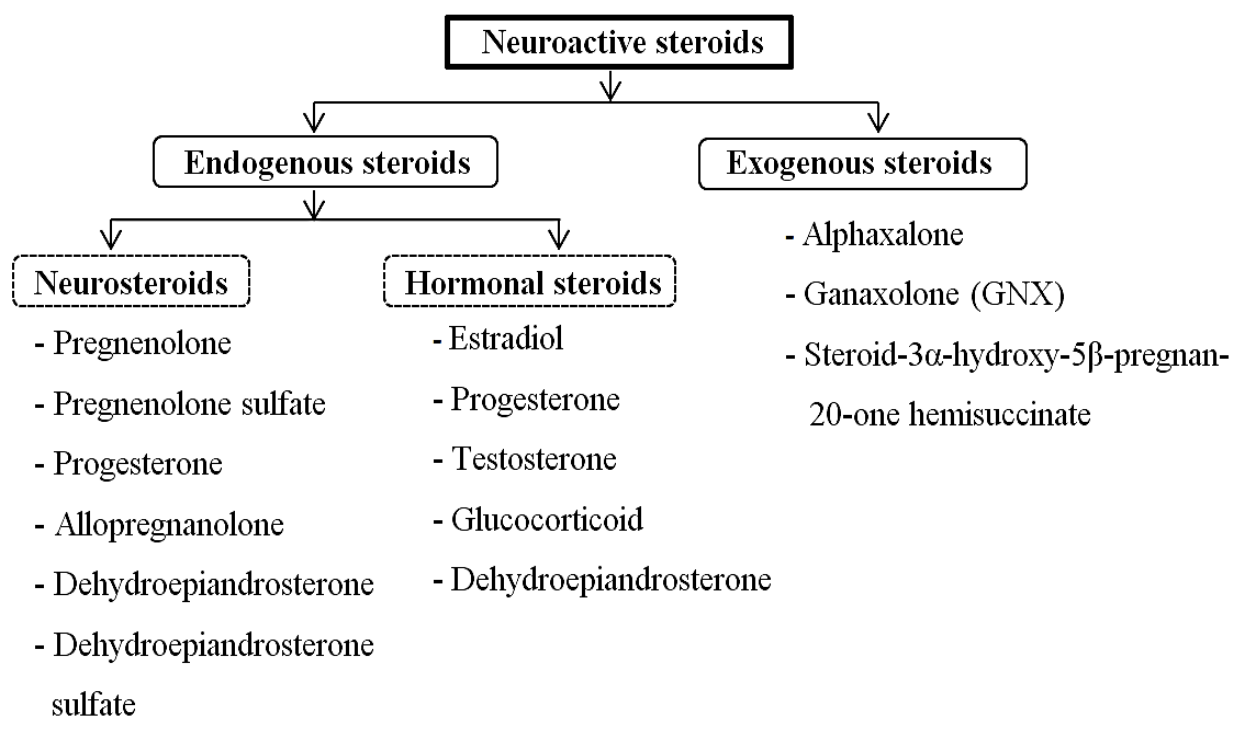

Figure 1: Classification of neuroactive steroids. ${ }^{2}$

Table 1: IUPAC and conventional nomenclature. ${ }^{5}$

\begin{tabular}{|c|c|c|}
\hline IUPAC name & Conventional (trivial) names & Abbreviation \\
\hline $3 \alpha$-hydroxy-5 $\alpha$-pregnan-20-one & $\begin{array}{c}5 \alpha \text {-pregnane- } 3 \alpha \text {-ol-20-one, } \\
3 \alpha, 5 \alpha \text {-tetrahydroprogesterone, } \\
\text { allopregnanolone }\end{array}$ & $3 \alpha, 5 \alpha-$ THP \\
\hline $3 \alpha$-hydroxy-5 $\beta$-pregnan-20-one & $\begin{array}{c}5 \beta \text {-pregnane- } 3 \alpha \text {-ol-20-one, } \\
3 \alpha, 5 \beta \text {-tetrahydroprogesterone, } \\
\text { pregnanolone }\end{array}$ & $3 \alpha, 5 \beta-\mathrm{THP}$ \\
\hline $3 \alpha, 21$-dihydroxy-5 $\alpha$-pregnan-20-one & $\begin{array}{c}5 \alpha \text {-pregnan-3 } \alpha, 21 \text {-diol-20-one, } \\
3 \alpha, 5 \alpha \text {-tetrahydrodeoxycorticosterone }\end{array}$ & $3 \alpha, 5 \alpha-$ THDOC \\
\hline $3 \alpha, 21$-dihydroxy-5 $\beta$-pregnan-20-one & $\begin{array}{c}5 \beta \text {-pregnan-3 } \alpha, 21 \text {-diol-20-one, } \\
3 \alpha, 5 \beta \text {-tetrahydrodeoxycorticosterone }\end{array}$ & $3 \alpha, 5 \beta-$ THDOC \\
\hline
\end{tabular}

IUPAC: International Union of Pure and Applied Chemistry; THP: Tetrahydroprogesterone; THDOC: Tetrahydrodeoxycorticosterone. 


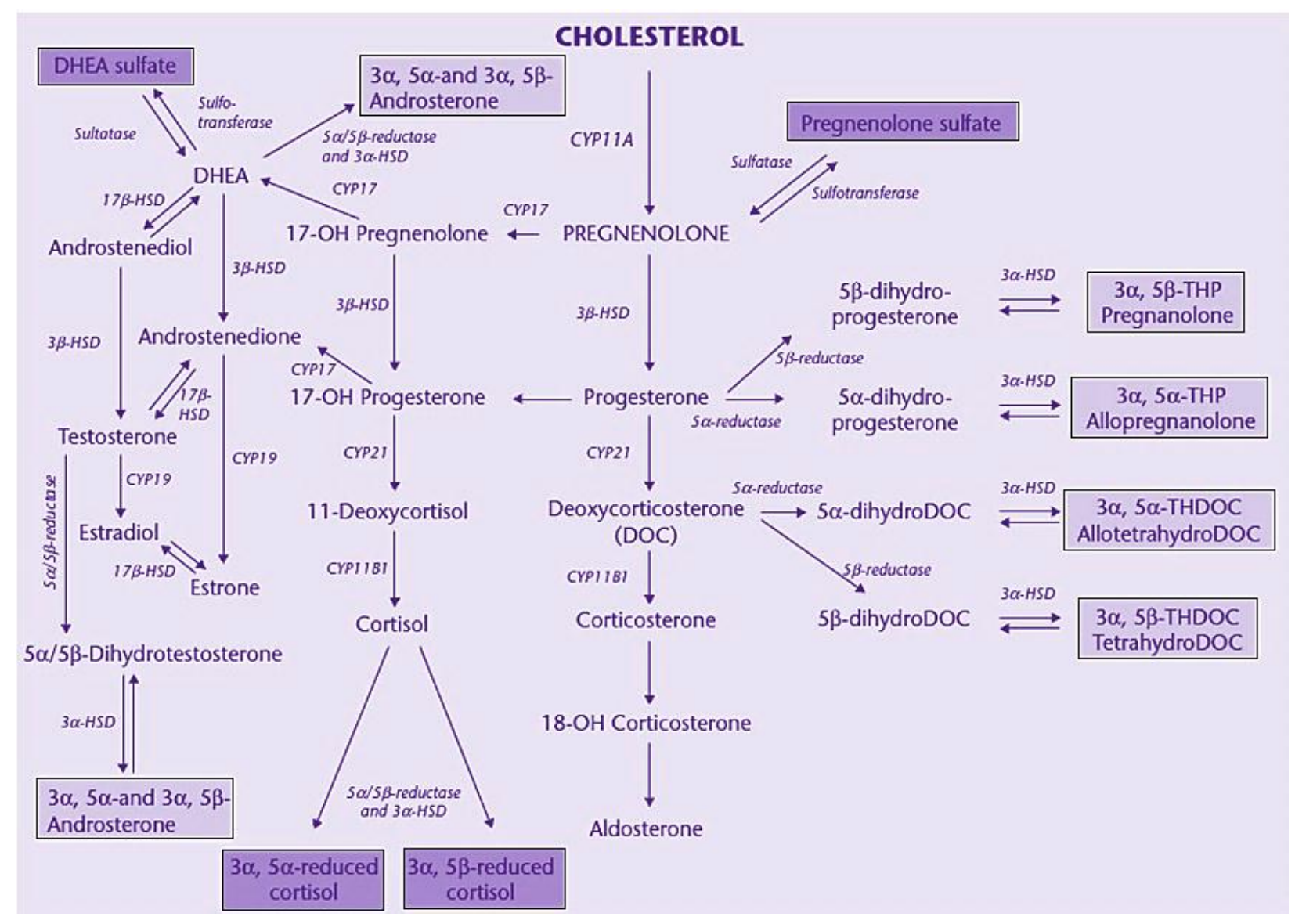

Figure 2: The biosynthetic pathway for neuroactive steroids. ${ }^{5}$

The inhibitory neuroactive steroids with potent $\mathrm{GABA}_{\mathrm{A}}$ receptor-positive modulatory effects are highlighted in light blue box; whereas the excitatory neuroactive steroids with weak $\mathrm{GABA}_{\mathrm{A}}$ receptor antagonist effects are highlighted in dark blue box.
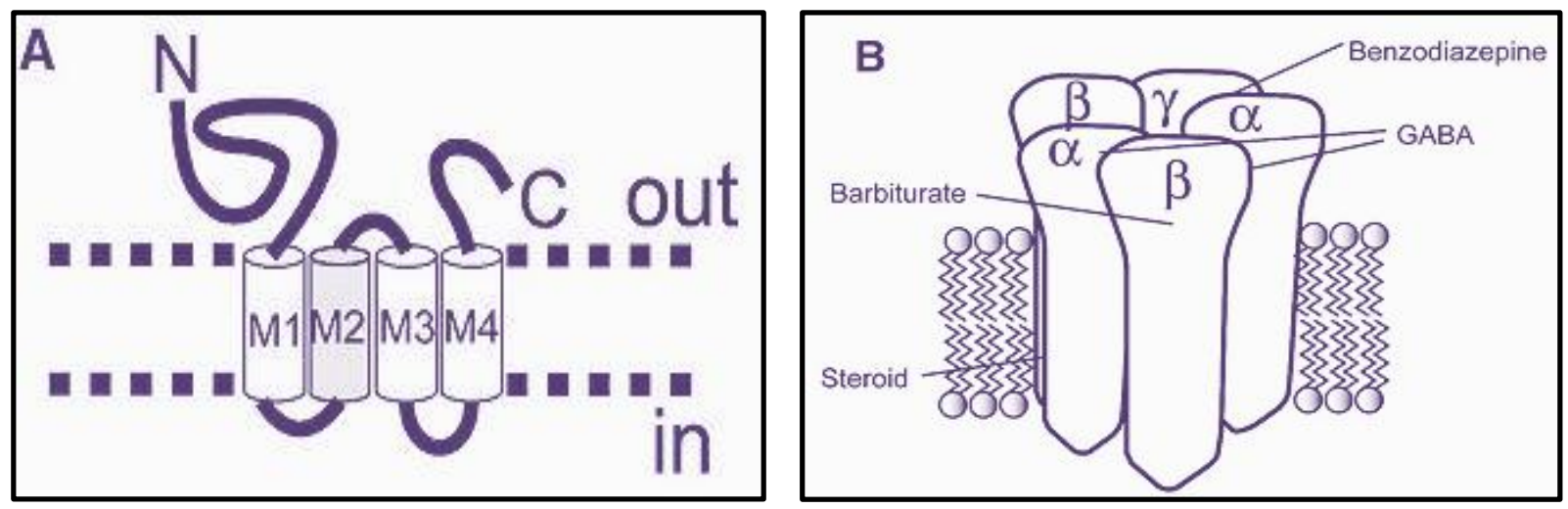

Figure 3 (A and B): Schematic and binding sites of $\mathbf{G A B A}_{\mathrm{A}}$ receptor ${ }^{7}$, (A) A single subunit of the $\mathrm{GABA}_{\mathrm{A}}$ receptor, highlighting topology. M1-M4 represent transmembrane domains. The M2 transmembrane domain forms an important part of the chloride channel pore. (B) Pentameric structure of a typical $\mathrm{GABA}_{\mathrm{A}}$ receptor. Several putative sites of modulatory drugs, including neurosteroids, are shown. It also shows steroids act on the $\mathrm{GABA}_{\mathrm{A}}$ receptor from within the transmembrane domains which is supported by pharmacological studies and by recent site-directed mutagenesis studies. 


\section{MODULATION OF GABA RECEPTORS BY NEUROACTIVE STEROID}

\section{$G A B A_{A}$ receptors}

GABA receptors are pentameric-heteromer and belong to the Cys-loop family of ligand-gated ion channels. ${ }^{1,7}$ Though the GABA-gated conductance has inhibitory influence on the cell, postsynaptic GABA response can be excitatory or inhibitory. Variations in $\mathrm{GABA}_{\mathrm{A}}$ receptors depend upon structure of the subunits. Functional channels of $\mathrm{GABA}_{\mathrm{A}}$ receptor are formed by the assembly of two $\alpha$ subunits (from $\alpha 1, \alpha 2, \alpha 3, \alpha 4, \alpha 5$, $\alpha 6$ ), two $\beta$ subunits (from $\beta 1, \beta 2, \beta 3$ ) plus one additional subunit, often a $\gamma$ subunit (from $\gamma 1, \gamma 2, \gamma 3$ ) but sometimes from a $\delta, \varepsilon, \pi$, or $\theta$ subunit. ${ }^{7}$ The $\alpha 1 \beta 2 \gamma 2$ subunit combination is the most common combination in the mammalian brain. ${ }^{7}$ Moreover, the $\gamma 2$ subunit is particularly important for synaptic localization/clustering of $\mathrm{GABA}_{\mathrm{A}}$ receptors as it contains sequence motifs, which are responsible for synaptic targeting.

A schematic of a single $\mathrm{GABA}_{\mathrm{A}}$ receptor subunit and the pentameric receptor with sites of action for important modulatory drugs are shown in Figure $3 \mathrm{~A}$ and $3 \mathrm{~B}$ respectively. $^{7}$

\section{Interaction with $\mathrm{GABA}_{A}$ receptors}

The $3 \alpha$-reduced metabolites of progesterone and deoxycorticosterone ( $3 \alpha, 5 \alpha$-tetrahydroprogesterone $/ 3 \alpha, 5 \alpha$-THP and $3 \alpha, 5 \alpha$ tetrahydrodeoxycorticosterone $13 \alpha, 5 \alpha$-THDOC respectively) were the first steroids that have shown to have modulatory effect on neuronal excitability via their interaction with GABA type A receptors. ${ }^{1,6}$ The most prominent interaction of neurosteroids with $\mathrm{GABA}_{\mathrm{A}}$ receptors is potentiating action rather antagonistic actions and is seen with the endogenous $3 \alpha, 5 \alpha$-THP (allopregnanolone), 3 $\alpha, 5 \beta$-THP (pregnanolone), $3 \alpha 5 \alpha$-THDOC and $3 \alpha 5 \beta$-THDOC. ${ }^{1,5,6,7}$ This positive allosteric modulatory action is because they enhance the GABA-evoked chloride current either by increasing frequency and/or by increasing duration of openings of the GABA-gated chloride channel. ${ }^{5,7,8}$ As neurosteroids are synthesized from cholesterol via progesterone or deoxycorticosterone; therefore, fluctuations in their levels may influence the modulatory effects that neurosteroids have over the function of the $\mathrm{GABA}_{\mathrm{A}}$ receptors.

Non-competitive antagonist action is seen with steroids sulfated at C3, typified by pregnenolone sulfate (PS) and sulfated pregnane steroids, with either $\alpha$ or $\beta$ stereochemistry at $\mathrm{C} 3$ and at $\mathrm{C} 5 .^{5,7}$ The $\mathrm{IC}_{50}$ (half maximal inhibitory concentration) values for the action of this class of neuroactive steroids is typically in the high nanomolar to micromolar range. Finally, $3 \beta-\mathrm{OH}$ steroids can also antagonize $\mathrm{GABA}_{\mathrm{A}}$ receptors but the potency and perhaps efficacy of $3 \beta-\mathrm{OH}$ steroids is weaker than that of sulfated steroids. ${ }^{7}$
Recent studies have shown evidence of two sites of neurosteroid action on $\mathrm{GABA}_{\mathrm{A}}$ receptors. One site spans the M1 and M4 transmembrane domains of the $\alpha$-subunit and accounts for the potentiating actions of some steroids. Another site, between the M1 domain of the $\alpha$ subunit and the M3 domain of the $\beta$-subunit, is responsible for direct gating of the channel by steroids. Schematic representation of these sites is shown in Figure 4. ${ }^{7}$ Various studies conducted have shown direct gating by steroids is inefficient, with maximum responses less than the responses generated by saturating GABA. In spite of this, small currents resulting from direct gating can have a significant impact on cellular excitability. Furthermore, studies done recently have reported that the onset and offset kinetics of direct gating are particularly slow. ${ }^{7}$ This may be the reason which has led to an underappreciation of the potency of neurosteroids directly activating the channel.

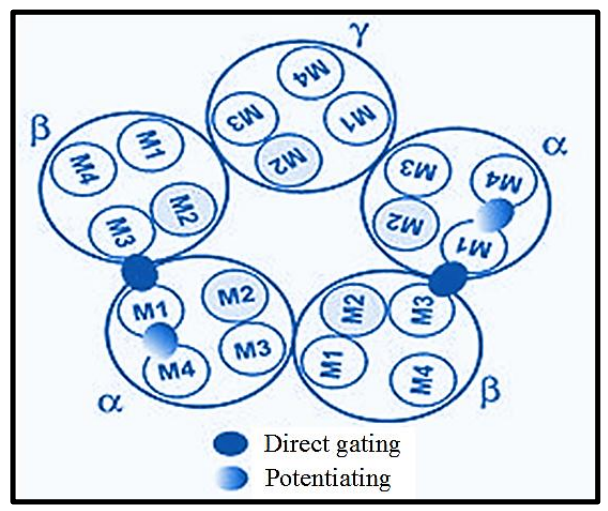

Figure 4: Top-down view of the pentameric $\mathrm{GABA}_{\mathrm{A}}$ receptor showing proposed sites of potentiation and direct gating for neurosteroids.

Neuroactive steroids are among the most potent and efficacious modulators of $\mathrm{GABA}_{\mathrm{A}}$ receptors. When compared with benzodiazepines their potency is less (half-maximum effects in the nanomolar concentration range), but generate higher maximum potentiation of GABA responses and therefore they are more efficacious. On the other hand, neuroactive steroids are less efficacious and more potent than barbiturate. ${ }^{7}$ Many review articles in the literature show that the action of neurosteroids is highly specific, being both brain region and neuron dependent. This selectivity is due to the composition of the $\mathrm{GABA}_{\mathrm{A}}$ receptor subunit, the differential expression of steroid-synthesizing and metabolizing enzymes, and local steroid metabolism and phosphorylation mechanisms. ${ }^{5,9}$ Neuroactive steroids act on both synaptic and extrasynaptic $\mathrm{GABA}_{\mathrm{A}}$ receptors. Moreover, extrasynaptic $\mathrm{GABA}_{\mathrm{A}}$ receptors are highly sensitive to neurosteroids ${ }^{9}$ and appear to play a vital role in the neuronal plasticity changes that accompany stress, puberty and the ovarian cycle.,

\section{Expression of the $\mathrm{GABA}_{A}$ receptors}

Previously, it was assumed that the neuroactive steroids do not regulate gene expression because they do not bind 
to a known intracellular steroid hormone receptor. Research done using a cotransfection system with recombinant progesterone receptors and the mouse mammary tumour virus (MTV) has shown that the neuroactive steroids like $3 \alpha, 5 \alpha$-THP and $3 \alpha, 5 \alpha$-THDOC activate gene expression effectively and enhance the nuclear translocation. ${ }^{1}$

Recently, it has been shown that both chronic exposure and withdrawal from exogenous neurosteroids increase expression of the $\mathrm{GABA}_{\mathrm{A}}$ receptor $\alpha 4$-subunit to produce CNS hyperexcitability. ${ }^{3}$ This increase in the expression of the $\alpha 4$-subunit is responsible for benzodiazepine insensitivity, one common factor in experimental rodent models and the clinical presentation of premenstrual dysphoric disorder.

\section{CLINICAL IMPORTANCE OF NEUROSTEROIDS IN EPILEPSY}

Neurosteroids including, allopregnanolone and tetrahydrodeoxycorticosterone (THDOC) that act as positive $\mathrm{GABA}_{\mathrm{A}}$ receptor modulators have shown to exhibit broad-spectrum anticonvulsant effects in diverse rodent seizure models. They protect against seizures induced by $\mathrm{GABA}_{\mathrm{A}}$ receptor antagonists including pentylenetetrazol (PTZ) and bicuculline and they are effective against pilocarpine-induced limbic seizures and seizures in kindled animals. ${ }^{10-13}$ Neurosteroids are also highly effective in suppressing seizures due to withdrawal of $\mathrm{GABA}_{\mathrm{A}}$ receptor modulator drugs including neurosteroids and benzodiazepines. However, it is seen in animal studies that neurosteroids may exacerbate generalized absence seizures. ${ }^{4,14,15}$ Neurosteroids differ from benzodiazepine that they do not act on the benzodiazepine site of $\mathrm{GABA}_{\mathrm{A}}$ receptors and also they are able to modulate all isoforms of $\mathrm{GABA}_{\mathrm{A}}$ receptors, including benzodiazepine-insensitive one. As a result anticonvulsant tolerance is not seen with neurosteroids in contrast to benzodiazepines. ${ }^{16,17}$ Thus, neurosteroids have the potential to be used in the chronic treatment of epilepsy and laid the basis for clinical trials.

The sulfated neurosteroids pregnenolone sulfate and dehydroepiandosterone sulfate, which act as $\mathrm{GABA}_{\mathrm{A}}$ receptor antagonists are proconvulsant when administered at high doses into the brain, producing seizures and status epilepticus. ${ }^{18}$ It is unlikely that they exist endogenously even if they do, their concentrations is not sufficiently high to exert proconvulsant effects. Therefore, their physiological relevance is unclear. However, it is known that the proconvulsant effects of these steroids can be blocked by co-administration of allopregnanolone or other neurosteroids that positively modulate $\mathrm{GABA}_{\mathrm{A}}$ receptors. ${ }^{19}$ There is some limited evidence that endogenous neurosteroids play a role in regulating epileptogenesis making them potentially useful for disease modifying therapeutic activity. ${ }^{20-22}$
Ganaxolone, the synthetic 3b-methyl analogue of allopregnanolone ( $3 \alpha$ - hydroxy-3 $\beta$-methyl-5 $\alpha$-pregnan20 -one) is the only neurosteroid that has been evaluated in human clinical trials for the treatment of epilepsy. ${ }^{23}$ Various safety and pharmacokinetic studies conducted on human subjects including children have shown that ganaxolone is well tolerated. However, it is associated with dose limiting adverse effects such as sedation and somnolence which are reversible. Ganaxolone is metabolized by CYP3A to 16-hydroxyganaxolone, which is inactive and then to various multihydroxylated metabolites. Despite the metabolism by microsomal enzyme, the information available to date indicates that ganaxolone will have low drug-drug interactions. ${ }^{4,24}$ Therefore, it could be administered easily with concomitant antiepileptic drugs. However, clinical trials having large sample size and with randomized, controlled and double blind study design are needed before its use in clinical practice.

\section{Catamenial Epilepsy}

Catamenial epilepsy is a form of pharmacoresistant epilepsy in which seizure exacerbations occur in cyclical manner during particular phases of the menstrual cycle in women with pre-existing epilepsy. It is estimated that up to $70 \%$ of women of child-bearing age with epilepsy experience catamenial seizure exacerbations. ${ }^{25-27}$ Catamenial epilepsy is classified into three forms: (1) perimenstrual ( $\mathrm{C} 1$ : days -3 to 3 ) and (2) periovulatory (C2: days 10 to -13$)$ in normal cycles, and (3) luteal (C3: days 10 to 3 ) in inadequate luteal phase cycles, wherein day 1 is the first day of menstrual flow and ovulation is presumed to occur 14 days before the subsequent onset of menses (day -14). ${ }^{24}$ Neurosteroids have been implicated only in the seizure exacerbations which occur during perimenstrual period which is also the most common form of catamenial epilepsy. It is hypothesized that withdrawal of progesterone derived neurosteroids predispose to seizure because of enhanced brain excitability.

During follicular phase of the menstrual cycle, circulating progesterone along with its metabolite allopregnanolone levels are low but their level rise in the mid-luteal phase for about 10 to 11 days. However during late luteal phase circulating progesterone levels decline causing withdrawal of the anticonvulsant effects of neurosteroids. ${ }^{28}$ Circulating THDOC levels though lower than those of allopregnanolone fluctuate during the menstrual cycle, with higher levels in the luteal phase. Study done recently suggested that serum THDOC levels could contribute to catamenial epilepsy, but it appears to be less relevant. ${ }^{4,24}$ An important question, whether the local brain synthesis of neurosteroids also fluctuates is still unanswered.

Pliability in $\mathrm{GABA}_{\mathrm{A}}$ receptors during perimenstrual period is also thought to play a role in the enhanced brain excitability, which leads to increase in seizure susceptibility in perimenstrual catamenial epilepsy. ${ }^{24}$ 
However, there is a lack of conclusive evidence that changes in expression of brain $\mathrm{GABA}_{\mathrm{A}}$ receptor subunit occurs during the human menstrual cycle. Studies in rats have shown that prolonged exposure to allopregnanolone causes increased expression of the $\alpha 4 \mathrm{GABA}_{\mathrm{A}}$ receptor subunit in hippocampus. This results in decreased benzodiazepine sensitivity of $\mathrm{GABA}_{\mathrm{A}}$ receptor as benzodiazepines only act on $\mathrm{GABA}_{\mathrm{A}}$ receptors containing $\gamma 2$ subunits and not containing $\alpha 4$ or $\alpha 6$ subunits. $^{29}$ Treatment of rats with allopregnanolone also results in transient increased expression of the $\delta$ subunit in hippocampus. It can coassemble with $\alpha 4$ to form nonsynaptic (perisynaptic/extrasynaptic) $\mathrm{GABA}_{\mathrm{A}}$ receptors and increased benzodiazepine-insensitive tonic current. $^{30,31}$ However, it is unclear that increased $\delta$ subunit expression has relevance in catamenial epilepsy as increase in $\delta$ subunit may be transitory.

Therefore, an important result of increased $\alpha 4$ subunit into synaptic $\mathrm{GABA}_{\mathrm{A}}$ receptors causes accelerated decay of synaptic currents generated by these receptors, which results in reduced inhibition. ${ }^{32}$ Neurosteroids cause a prolongation of the decay of GABA-mediated synaptic currents. As a result during the luteal phase, presence of high levels of allopregnanolone and the acceleration due to $\alpha 4$ substitution are balanced. ${ }^{24}$ However, at the time of menstruation when neurosteroids are withdrawn; synaptic inhibition is diminished resulting in enhanced excitability predisposing to seizures.

The neurosteroid withdrawal rodent model of catamenial epilepsy was used to investigate therapies for perimenstrual catamenial epilepsy. ${ }^{33,34}$ A major outcome was that conventional antiepileptic drugs, like benzodiazepines and valproate, have reduced potency in protecting against seizures during the period of enhanced seizure susceptibility following neurosteroid withdrawal. This situation was similar to the catamenial epilepsy in women where breakthrough seizures occur despite treatment with antiepileptic drugs. Moreover, neurosteroids including allopregnanolone, THDOC and their $5 \beta$-isomers, were found to have enhanced activity in the perimenstrual catamenial epilepsy model. ${ }^{33}$ This suggested a novel approach of "neurosteroid replacement" for the treatment of catamenial seizure exacerbations. ${ }^{24}$

While neurosteroid reduction by itself does not lead to epilepsy, it is well established that endogenous neurosteroids do modulate seizure susceptibility in epileptic animals. Moreover, in the catamenial epilepsy model neurosteroid withdrawal causes markedly greater seizure provocation, consistent with earlier studies demonstrating enhanced seizure susceptibility in acute seizure models. Importantly, it supports the concept that neurosteroid replacement may be useful in the treatment of seizures associated with neurosteroid fluctuations such as catamenial epilepsy. ${ }^{35}$ Although neurosteroids seems to be the most direct approach to the treatment of catamenial epilepsy, there is only limited circumstantial data available to support their use. ${ }^{36}$

A neurosteroid could be administered in a "pulse" prior to menstruation but continuous administration throughout the month is preferred. Continuous administration would avoid withdrawal of the therapeutic agent, which itself could predispose to seizures, also there is difficulty in predicting the time of menstrual periods in many women. They are administered at low doses to avoid sedative side effects. Though, it contributes little to anticonvulsant activity during most of the menstrual cycle, at the time of menstruation increased potency of the neurosteroid would confer protection against perimenstrual seizure exacerbations. It is noteworthy that there is no corresponding increases in side effects (mainly sedation). ${ }^{24}$ Therefore, enhanced side effects which would negate the potential of the therapeutic approach, would not be expected to occur.

No neurosteroid is currently approved. The data from human clinical trials suggests that adjunctive cyclic progesterone supplementation may be useful in women with catamenial epilepsy. ${ }^{37,38}$ However, there are chances that Progesterone therapy in women may cause hormonal effects such as breakthrough vaginal bleeding, breast tenderness, weight gain, sedation and emotional depression. In the treatment regimen used in the clinical trials, progesterone is administered only after cycle day 14 and is tapered and discontinued during days 26 to 28 , as it is believed that starting earlier than mid-cycle would interfere with normal cycling causing irregular bleeding and abrupt discontinuation can result in rebound seizure exacerbation. An advantage of hormonally-inactive neurosteroids is that they have no hormonal adverse effects and can be administered throughout the cycle, simplifying the treatment regimen. ${ }^{24,36}$

Preliminary uncontrolled open label study was conducted to evaluated safety and efficacy of ganaxolone in women with catamenial epilepsy. ${ }^{22,24,36}$ These women received oral ganaxolone $(300 \mathrm{mg} / \mathrm{day}$, twice a day) starting on day 21 of the menstrual cycle and continued up to third day of next menstrual cycle. It showed that ganaxolone appeared to reduce their catamenial seizures. Study also showed that it was well tolerated and was associated with no hormonal adverse effects. However, further clinical trial with a randomized, controlled study design is required before this agent can be recommended for clinical use.

\section{Stress-Induced Seizure}

Body respond to physiological stress by increasing circulating levels of neurosteroids. Stress results in stimulation of hypothalamo-pituitary-adrenal (HPA) axis leading to enhanced synthesis of adrenal cortisol and neurosteroid, deoxycorticosterone (DOC).$^{39,40}$ THDOC is derived nearly exclusively from adrenal sources, while allopregnanolone is derived either from brain, adrenal gland and/or gonads proved in animal studies. ${ }^{41}$ Acute 
stress such as swimming, foot shock or carbon dioxide exposure elicit rapid rise in plasma and brain levels of THDOC and allopregnanolone. ${ }^{41-43}$ Normal plasma levels of THDOC fluctuate between 1 and $5 \mathrm{nM}$, but following the acute stress it increase to $15-30 \mathrm{nM}$ and might reach 40-60 nM during pregnancy. On the other hand, allopregnanolone levels typically reach 70-160 nM during the third trimester of pregnancy and have been measured as high as $220 \mathrm{nM}^{44}$

Various animal studies have shown that stress-induced neurosteroids elevate seizure threshold and have anticonvulsant effects against seizures induced by PTZ and other $\mathrm{GABA}_{\mathrm{A}}$ receptor antagonists. ${ }^{41}$ This anticonvulsant action of stress induced neurosteroids could be due to circulating neurosteroids synthesized in peripheral tissues or to those produced locally in the brain. Though, stress-induced enhanced neurosteroid production and their protective effect against seizure is seen in animals, ${ }^{41}$ it is unlikely to see reduction in seizure frequency associated with stress in epileptic patients. Indeed, stress has been reported to trigger seizure activity in persons with epilepsy. ${ }^{45}$ During the stressful episodes, it is expected to have fluctuation in adrenal hormone levels and may be the withdrawal of THDOC during such fluctuations is associated with seizure provocation. Alternatively, other unidentified hormonal factors with proconvulsant activity may be responsible for stressinduced increases in seizures. However, the type of stress experienced by patients with epilepsy is a chronic type, and it is likely that it has different endocrinological consequences than acute stress. The effects of fluctuations in neurosteroids on seizures in chronic stress remain to be studied.

\section{Temporal Lobe Epilepsy}

Epilepsy is commonly associated with sexual and reproductive dysfunction. ${ }^{46}$ Patients of temporal lobe epilepsy (TLE) particularly men often have diminished libido and sexual potency that is associated with low testosterone levels. ${ }^{47}$ There are two factors which can be attributed to this hypogonadal state, firstly, effects of certain hepatic enzyme-inducing antiepileptic drugs and secondly, the connections between temporal lobe structures such as the amygdala and hypothalamic nuclei that governs the production and secretion of gonadotropin releasing hormone, which is responsible for suppression of the hypothalamic-pituitary-gonadal axis by limbic seizures. $^{46,47}$

A study conducted on men have shown that after temporal lobe epilepsy surgery, serum androgens level becomes normal which results in successful seizure control. However, normalization of serum androgens is not seen in those that continue to have seizures, supporting the observation that seizures are responsible for the hypoandrongenic state. ${ }^{48}$ As noted earlier, testosterone serves as a precursor for neurosteroids like androstanediol which are a positive modulator of $\mathrm{GABA}_{\mathrm{A}}$ receptor that is responsible for their anticonvulsant properties. $^{4,49,50}$ Studies have shown that serum levels of these neurosteroids are reduced in men with epilepsy compared with control subjects. ${ }^{4}$ Therefore, neurosteroid replacement might be a useful therapeutic approach.

However in temporal lobe epilepsy there are some biological factors which may influence the sensitivity of endogenous neurosteroids and therefore could have an influence on the efficacy of exogenous neurosteroids used in epilepsy therapy. Studies in a status epilepticus model of TLE have shown that in the dentate gyrus there is a reduction in $\delta$-subunit containing $\mathrm{GABA}_{\mathrm{A}}$ receptors, ${ }^{51}$ also the neurosteroids modulation of synaptic currents is diminished along with presence of $\alpha 4$ subunit containing receptors at synapses. ${ }^{52}$ All of these changes may reduce the efficacy of endogenous neurosteroids and may facilitate seizures in epileptic animals. Therefore, before considering the neurosteroid replacement therapy in TLE these biological factures should be considered.

\section{Alcohol Withdrawal Seizures}

Ethanol, when administered systemically at moderate doses of $(1-2.5 \mathrm{~g} / \mathrm{kg})$ is believed to activate HPA axis. This causes increase in plasma and brain neurosteroids that may contribute to many of the it's behavioural effects in rodents. ${ }^{53}$ Chronic ethanol administration causes elevation of neurosteroids like, allopregnanolone and THDOC and their enhanced anticonvulsant actions These effects are associated with increases in the sensitivity of $\mathrm{GABA}_{\mathrm{A}}$ receptors to neurosteroids. ${ }^{53}$ Though endogenous neurosteroids may protect against ethanol withdrawal seizures but, ethanol induction of allopregnanolone is diminished in tolerant and dependent animals. Reduced availability of allopregnanolone under such circumstances may be a factor that predisposes to alcohol withdrawal seizures. Therefore, neurosteroid replacement could possibly be useful in the treatment of alcohol withdrawal seizures. ${ }^{54}$

\section{Status Epilepticus}

Status epilepticus is an emergency neurological condition. It is characterized by persistent seizures lasting more than 30 minutes, resistance to benzodiazepine treatment and progressive internalization of synaptic $\mathrm{GABA}_{\mathrm{A}}$ receptors. Therefore, new therapies with novel mechanism of actions are needed for refractory status epilepticus. ${ }^{4}$ During the attack of status epilepticus, the extra synaptic $\delta$-subunit containing $\mathrm{GABA}_{\mathrm{A}}$ receptors that generate "tonic" inhibition do not internalize. Considering this factor, neurosteroids having positive modulatory action on $\mathrm{GABA}_{\mathrm{A}}$ receptors with strong anticonvulsant activity, could be more effective for treatments of status epilepticus. ${ }^{4,55}$ Preclinical studies involving animal model have shown that neurosteroids like THDOC can effectively terminate chemically electrographic and behavioural status epilepticus. ${ }^{55}$ Treatment with THDOC successfully aborted seizures with sustained suppression of status epilepticus, with efficacy superior to the benzodiazepine. In addition, THDOC therapy may confer significant neuroprotection 
by diminishing the neuronal cell death associated with status epilepticus. Further studies are needed to clarify whether neurosteroids might be valuable in the treatment of status epilepticus.

\section{Infantile Spasm}

Infantile spasm is catastrophic form of epileptic encephalopathy in infants and young children. ACTH has been used for many years as a treatment for infantile spasms. Despite the numerous studies in literature reporting effectiveness of $\mathrm{ACTH}$ and oral steroids in treatment of infantile spasm, the exact mechanism is unknown. ${ }^{56}$ Clinical benefits of ACTH in infantile spasms thought to be due to release of adrenocorticosteroids and neurosteroids. Recent studies show that several newer anticonvulsant agents (such as vigabatrin and benzodiazepines), which are positive allosteric modulators of $\mathrm{GABA}_{\mathrm{A}}$ receptors, are as effective as ACTH in acutely controlling infantile spasms. Ganaxolone, a novel neuroactive steroid, however has demonstrated better efficacy and tolerability in children with intractable infantile spasms. Results of an open-label, add-on trial of ganaxolone showed that it is safe and effective in treating refractory infantile spasms patients. $^{57}$ However further investigation is required before starting its clinical use.

\section{CONCLUSIONS}

Awareness of the prominent role of neurosteroids in neurological disorders is rapidly increasing. Numerous basic and clinical investigations carried out over the past few year support their central role in normal physiological functioning as well as in illness. Neurosteroids that are positive modulator of $\mathrm{GABA}_{\mathrm{A}}$ receptor have potent anticonvulsants action and may regulate various neuronal excitability networks. Neurosteroids are believed to play a role in the regulation of seizure susceptibility in the setting of pre-existing epilepsy. Although, preliminary investigation into the use of neurosteroid analogues or manipulation of the neurosteroid system in treatment remain promising, such as the use of ganaxolone in epilepsy. Further studies are required to determine whether "neurosteroid replacement" is a useful approach for epileptic seizures related to endogenous neurosteroid fluctuations, such as in catamenial epilepsy.

\section{Funding: No funding sources \\ Competing interests: There are no competing interests to declare}

\section{REFERENCES}

1. Rupprecht R. Neuroactive steroids: Mechanisms of action and neuropsychopharmacological properties. Psychoneuroendocrinology 2003;28:139-68.

2. Zheng P. Neuroactive steroid regulation of neurotransmitter release in the CNS: Action, mechanism and possible significance. Prog Neurobiol 2009;89:134-52.

3. Melcangi RC, Panzica G, Garcia-Segura LM. Neuroactive steroids: Focus on human brain. Neuroscience 2011;191:1-5.

4. Reddy DS. Role of anticonvulsant and antiepileptogenic neurosteroids in the pathophysiology and treatment of epilepsy. Front Endocrinol (Lausanne) 2011;2:38.

5. Morrow AL. Recent developments in the significance and therapeutic relevance of neuroactive steroids--Introduction to the special issue. Pharmacol Ther 2007;116:1-6.

6. Rupprecht R, di Michele F, Hermann B, Ströhle A, Lancel M, Romeo E, et al. Neuroactive steroids: Molecular mechanisms of action and implications for neuropsychopharmacology. Brain Res Brain Res Rev 2001;37:59-67.

7. Akk G, Covey DF, Evers AS, Steinbach JH, Zorumski CF, Mennerick S. Mechanisms of neurosteroid interactions with $\operatorname{GABA}(\mathrm{A})$ receptors. Pharmacol Ther 2007;116:35-57.

8. Mellon SH, Griffin LD. Neurosteroids: Biochemistry and clinical significance. Trends Endocrinol Metab 2002;13:35-43.

9. Herd MB, Belelli D, Lambert JJ. Neurosteroid modulation of synaptic and extrasynaptic GABA(A) receptors. Pharmacol Ther 2007;116:20-34.

10. Kokate TG, Svensson BE, Rogawski MA. Anticonvulsant activity of neuroactive steroids: correlation with gamma-aminobutyric acid-evoked chloride current potentiation. J Pharmacol Exp Ther 1994;270:1223-9.

11. Belelli D, Bolger MB, Gee KW. Anticonvulsant profile of the progesterone metabolite 5 $\alpha$-pregnan3 $\alpha$-ol-20-one. Eur J Pharmacol 1989;166:325-9.

12. Frye CA. The neuroactive steroid $3 \alpha, 5 \alpha$-THP has anti-seizure and possible neuroprotective effects in an animal model of epilepsy. Brain Res 1995;696:113-20.

13. Wieland S, Belluzzi JD, Stein L, Lan NC. Comparative behavioral characterization of the neuroactive steroids $3 \alpha-\mathrm{OH}, 5 \alpha$-pregnan-20-one and $3 \alpha-\mathrm{OH}, 5 \beta$-pregnan-20-one in rodents. Psychopharmacology 1995;118:65-71.

14. Citraro R, Russo E, Di Paola ED, Ibbadu GF, Gratteri S, Marra R, De Sarro G. Effects of some neurosteroids injected into some brain areas of WAG/Rij rats, an animal model of generalized absence epilepsy. Neuropharmacology 2006;50:1059-71.

15. Snead OC 3rd. Ganaxolone, a selective, highaffinity steroid modulator of the $\gamma$-aminobutyric acid-A receptor, exacerbates seizures in animal models of absence. Ann Neurol 1998;44:688-91.

16. Reddy DS, Rogawski MA. Chronic treatment with the neuroactive steroid ganaxolone in the rat induces anticonvulsant tolerance to diazepam but not to itself. J Pharmacol Exp Ther 2000;295:1241-8. 
17. Kokate TG, Yamaguchi S, Pannell LK, Rajamani U, Carroll DM, Grossman AB, Rogawski MA. Lack of anticonvulsant tolerance to the neuroactive steroid pregnanolone in mice. $\mathbf{J}$ Pharmacol Exp Ther 1998;287:553-8.

18. Williamson J, Mtchedlishvili Z, Kapur J. Characterization of the convulsant action of pregnenolone sulfate. Neuropharmacology 2004;46:856-64.

19. Reddy DS, Kulkarni SK. Proconvulsant effects of neurosteroid pregnenolone sulfate and dehydroepiandrosterone sulfate in mice. Eur $\mathbf{J}$ Pharmacol 1998;345:55-9.

20. Biagini G, Panuccio G, Avoli M. Neurosteroids and epilepsy. Curr Opin Neurol 2010;23:170-6.

21. Biagini G, Longo D, Baldelli E, Zoli M, Rogawski MA, Bertazzoni G, Avoli M. Neurosteroids and epileptogenesis in the pilocarpine model: Evidence for a relationship between $\mathrm{P} 450 \mathrm{scc}$ induction and length of the latent period. Epilepsia 2009;50 Suppl 1:53-8.

22. Biagini G, Baldelli E, Longo D, Pradelli L, Zini I, Rogawski MA, Avoli M. Endogenous neurosteroids modulate epileptogenesis in a model of temporal lobe epilepsy. Exp Neurol 2006;201:519-24.

23. Monaghan EP, McAuley JW, Data JL. Ganaxolone: a novel positive allosteric modulator of the GABAA receptor complex for the treatment of epilepsy. Expert Opin Investig Drugs 1999;8:1663-71.

24. Reddy DS, Rogawski MA. Neurosteroid replacement therapy for catamenial epilepsy. Neurotherapeutics 2009;6:392-401.

25. Reddy DS. The role of neurosteroids in the pathophysiology and treatment of catamenial epilepsy. Epilepsy Res 2009;85:1-30.

26. Bazan AC, Montenegro MA, Cendes F, Min LL, Guerreiro CA. Menstrual cycle worsening of epileptic seizures in women with symptomatic focal epilepsy. Arg Neuropsiguiatr 2005;63(3B):751-6.

27. Herzog AG, Harden CL, Liporace J, Pennell P, Schomer DL, Sperling M, Fowler K, Nikolov B, Shuman S, Newman M. Frequency of catamenial seizure exacerbation in women with localizationrelated epilepsy. Ann Neurol 2004;56:431-4.

28. Tuveri A, Paoletti AM, Orrù M, Melis GB, Marotto MF, Zedda P, Marrosu F, Sogliano C, Marra C, Biggio G, Concas A. Reduced serum level of THDOC, an anticonvulsant steroid, in women with perimenstrual catamenial epilepsy. Epilepsia 2008;49:1221-9.

29. Gangisetty O, Reddy DS. Neurosteroid withdrawal regulates $\mathrm{GABA}_{\mathrm{A}}$ receptor alpha4-subunit expression and seizure susceptibility by activation of progesterone receptor-independent early growth response factor-3 pathway. Neuroscience 2010; $170: 865-80$.

30. Shen H, Gong QH, Yuan M, Smith SS. Short-term steroid treatment increases $\delta$ GABAA receptor subunit expression in rat CA1 hippocampus: pharmacological and behavioral effects. Neuropharmacology 2005;49:573-86.

31. Maguire JL, Stell BM, Rafizadeh M, Mody I. Ovarian cycle-linked changes in GABAA receptors mediating tonic inhibition alter seizure susceptibility and anxiety. Nat Neurosci 2005;8:797-804.

32. Smith SS, Gong QH. Neurosteroid administration and withdrawal alter GABAA receptor kinetics in CA1 hippocampus of female rats. J Physiol 2005;564:421-36.

33. Reddy DS, Rogawski MA. Enhanced anticonvulsant activity of neuroactive steroids in a rat model of catamenial epilepsy. Epilepsia 2001;42:303-10.

34. Reddy DS, Rogawski MA. Enhanced anticonvulsant activity of ganaxolone after neurosteroid withdrawal in a rat model of catamenial epilepsy. J Pharmacol Exp Ther 2000;294:909-15.

35. Lawrence C, Martin BS, Sun C, Williamson J, Kapur J. Endogenous neurosteroid synthesis modulates seizure frequency. Ann Neurol 2010;67:689-93.

36. McAuley JW, Moore JL, Reeves AL, Flyak J, Monaghan EP, Data J. A pilot study of the neurosteroid ganaxolone in catamenial epilepsy: clinical experience in two patients. Epilepsia 2001;42:85.

37. Herzog AG, Fowler KM, Smithson SD, Kalayjian LA, Heck CN, Sperling MR, Liporace JD, Harden CL, Dworetzky BA, Pennell PB, Massaro JM. Progesterone vs placebo therapy for women with epilepsy: A randomized clinical trial. Neurology 2012;78:1959-66.

38. Herzog AG. Hormonal therapies: progesterone. Neurotherapeutics 2009;6:383-91.

39. Biggio G, Concas A, Follesa P, Sanna E, Serra M. Stress, ethanol, and neuroactive steroids. Pharmacol Ther 2007;116:140-71.

40. Reddy DS. Physiological role of adrenal deoxycorticosterone-derived neuroactive steroids in stress-sensitive conditions. Neuroscience 2006;138:911-20.

41. Reddy DS, Rogawski MA. Stress-induced deoxycorticosterone-derived neuroactive steroids modulates GABAA receptor function and seizure susceptibility. J Neurosci 2002;42:3795-805.

42. Barbaccia ML, Roscetti G, Trabucchi M, Mostallino MC, Concas A, Purdy RH, Biggio G. Timedependent changes in rat brain neuroactive steroid concentrations and GABAA receptor function after acute stress. Neuroendocrinology 1996;63:166-72.

43. Barbaccia ML, Roscetti G, Trabucchi M, Purdy RH, Mostallino MC, Concas A, Biggio G. The effects of inhibitors of GABAergic transmission and stress on brain and plasma allopregnanolone concentrations. Br J Pharmacol 1997;120:1582-8.

44. Parízek A, Hill M, Kancheva R, Havlíková H, Kancheva L, Cindr J, Pasková A, Pouzar V, Cerny I, Drbohlav P, Hájek Z, Stárka L. Neuroactive 
pregnanolone isomers during pregnancy. J Clin Endocrinol Metab 2005;90:395-403.

45. Frucht MM, Quigg M, Schwaner C, Fountain NB. Distribution of seizure precipitants among epilepsy syndromes. Epilepsia 2000;41:1534-9.

46. Edwards HE, MacLusky NJ, Burnham WM. Epileptic seizures: Do they cause reproductive dysfunction? Univ Toronto Med J 2000;77:104-11.

47. Herzog AG. Altered reproductive endocrine regulation in men with epilepsy: implications for reproductive function and seizures. Ann Neurol 2002;51:539-42.

48. Bauer J, Stoffel-Wagner B, Flügel D, Kluge M, Schramm J, Bidlingmaier F, Elger CE. Serum androgens return to normal after temporal lobe epilepsy surgery in men. Neurology 2000;55:82024.

49. Reddy DS. Anticonvulsant activity of the testosterone-derived neurosteroid $3 \alpha$-androstanediol. Neuroreport 2004; 15:515-8.

50. Reddy DS. Testosterone modulation of seizure susceptibility is mediated by neurosteroids $3 \alpha$ androstanediol and 17 $\beta$-estradiol. Neuroscience 2004;129:195-207.

51. Zhang N, Wei W, Mody I, Houser CR. Altered localization of GABAA receptor subunits on dentate granule cell dendrites influences tonic and phasic inhibition in a mouse model of epilepsy. J Neurosci 2007;27:7520-31.

52. Sun C, Mtchedlishvili Z, Erisir A, Kapur J. Diminished neurosteroid sensitivity of synaptic inhibition and altered location of the $\alpha 4$ subunit of GABAA receptors in an animal model of epilepsy. $J$ Neurosci 2007;27:12641-50.

53. Morrow AL, Porcu P, Boyd KN, Grant KA. Hypothalamic-pituitary-adrenal axis modulation of GABAergic neuroactive steroids influences ethanol sensitivity and drinking behavior. Dialogues Clin Neurosci 2006;8:463-77.

54. N'Gouemo P, Rogawski MA. Alcohol withdrawal seizures. In: Pitkänen A, Schwartzkroin PA, Moshé SL, editors. Models of Seizures and Epilepsy. Amsterdam: Elsevier Academic Press; 2006:161-77.

55. Kuruba R, Reddy DS. Neuroprotective effects of GABAergic agents in the rat model of refractory status epilepticus. Soc Neurosci Abstr 2011;PN 338.08.

56. Shields WD. Infantile Spasms: Little Seizures, BIG Consequences. Epilepsy Curr 2006;6:63-9.

57. Anovadiya AP, Sanmukhani JJ, Tripathi CB. Epilepsy: Novel therapeutic targets. J Pharmacol Pharmacother 2012;3:112-7.

doi: 10.5455/2319-2003.ijbcp004212

Cite this article as: Patil CY, Jadhav SA, Doifode SM, Baig MS. Neuroactive steroids and their role in epilepsy. Int J Basic Clin Pharmacol 2012;1:150-9. 